Sharon Kalsy Clinical Psychologist, Tudor Wing HIV and Sexual Health Service, The Hillingdon Hospital, Uxbridge, Middlesex

\section{Adverse Syndromes and Psychiatric Drugs: A Clinical Guide}

Peter Haddad, Serdar Dursan \& Bill Deakin (eds)

Oxford: Oxford University Press, 2004, f29.95 pb, $330 \mathrm{pp}$

ISBN: 0-19-852748-9

There are books to suit different purposes. For example, one may read a book for pleasure, use another for a particular reference and another still as an academic text. Then there is a book such as this one that fulfils all of these criteria.

This book covers a number of adverse syndromes associated with drugs used in psychiatry, including relatively common scenarios such as extrapyramidal sideeffects and extending to less wellunderstood phenomena such as diabetes mellitus and neuroleptic malignant syndrome. All the chapters follow the same format including sections on clinical features of the syndrome, differential diagnosis, management, risk factors and prevention, with a summary at the end.

There are few surprises in the recommendations, which on the whole appear to be in line with current practice guidelines, although less so with practice. One of the great strengths of the book is that it can be used as a guide to aid clinical practice rather than solely as an academic text

This book is a welcome addition to a slowly growing collection of practical guides on drugs used in psychiatry. It is a stimulating read and will appeal to academics and clinicians alike. I recommend it to psychiatrists, pharmacists, general practitioners, nurses and any other healthcare professionals involved with or interested in drug treatment in psychiatry.

Shubhra Mace Principal Clinical Pharmacist, South London and Maudsley NHS Trust

\section{Practical Management of Dementia - A Multi- Professional Approach}

Stephen Curran \& John Wattis Oxford: Radcliffe Medical Press, 2004, f27.95 pb, $248 \mathrm{pp}$ ISBN: 1857759311

This book brings together current scientific knowledge of dementia with the ways in which different professionals are involved in the process of care. It discusses models of service delivery such as memory clinics and gives guidance as to how one might ascertain local service needs and establish appropriate services. There are also chapters on specific aspects of dementia care. The spirituality chapter is illuminating and thoughtprovoking. Person-centred care is a theme which runs through the book and there is a good summary of its principles within the role of the nurse in dementia care. The occupational therapy chapter is well organised and informative with thoughtful case examples. The chapter on early-onset dementia is a useful reference for those not expert in the field. Legal aspects of dementia are clearly set out, although this area is equally well covered in the recent BMA publication on capacity (BMA \& Law Society, 2004). As the legal framework for decision-making for those with incapacity will undoubtedly soon change with impending legislation, this space could have perhaps been used more profitably. Supporting carers of people with dementia would have justified a chapter in its own right. Similarly greater emphasis could have been made of ways in which services can reach out to minority ethnic populations.

One criticism of the book is the amount of repetition which makes it difficult to read at one sitting. The chapters on epidemiology, diagnosis, early detection and memory clinics could have been rationalised. This would have allowed space to expand on topics such as neuropsychological assessment and psychological management techniques. The inclusion of the different perspectives of the old age psychiatrist, physician for the elderly and general practitioner provides valuable insights into the expertise and viewpoints of each. However, it also leads to some idiosyncrasies. It might have been helpful to have a clearly stated consensus opinion or a current summary of the debate in controversial areas, for example the place of neuroimaging in the routine assessment of dementia.

Overall the book successfully brings together the elements of good practice in delivering multidisciplinary care to dementia sufferers and their families. However, as the editors state, provision of such care is reliant on underpinning by sound political and financial support.

BMA \& LAW SOCIETY (2004) Assessment of Mental Capacity: Guidance for Doctors and Lawyers, 2nd edn. London: BMJ Books.

Rowena Jones Specialist Registrar in Old Age Psychiatry, Services for Older Adults, Queen Elizabeth Psychiatric Hospital, Mindelsohn Way, Edgbaston, Birmingham B15 2QZ 